\title{
Numerical investigation of heat transfer in 4-pass fire-tube boiler
}

\author{
Ahmed Rahmani ${ }^{1}$, Soumia Trabelsi ${ }^{2}$ \\ ${ }^{1}$ Department of Mechanical Engineering, University of Oum El Bouaghi, 04000, Algeria \\ ${ }^{2}$ Department of Chemical Engineering, University of Annaba, 23000, Algeria
}

Email address:

mag_phy@yahoo.fr(A. Rahmani),rahmani.ahmed@univ-oeb.dz (S. Trabelsi)

To cite this article:

Ahmed Rahmani, Soumia Trabelsi. Numerical Investigation of Heat Transfer in 4-Pass Fire-Tube Boiler. American Journal of Chemical Engineering. Vol. 2, No. 5, 2014, pp. 65-70. doi: 10.11648/j.ajche.20140205.12

\begin{abstract}
In this paper, the heat transfer in 4-pass 500HP fire-tube steam boiler is numerically investigated. A calculation program is carried out in order to simulate the heat transfer characteristics between the hot gases and the boiler tube internal walls. Especially, the heat flux densities and the corresponding wall temperatures for different operating conditions. On these surfaces, an energy balance is established taking into account the radiation and the convection heat transfer. The model validation consists in comparing the predicted outlet gas temperature with the operating data of the PFTA 500HP fire-tube boiler for several steady-state conditions. The comparison shows that the calculation results are in good agreement with the boiler operating data. Furthermore, a sensitivity study has been carried out to investigate the operating pressure effect on the boiler thermal performances.
\end{abstract}

Keywords: Fire-Tube Boiler, Combustion, Heat Transfer, Nucleate Boiling, Radiation, Convection

\section{Introduction}

Fire-tube boilers are widely used for modest steam output at low and medium pressures. They can either deliver hot water or steam for heating and technological purposes. In the past few years, improvement in boiler designs and more efficient fire-tube layout have resulted in more compact, less costly packages which are more accessible for cleaning and inspection $[1,2]$. Accurate prediction of heat transfer in the boiler is of significant importance for safe and economic operation [3]. Several numerical and experimental studies $[4,5]$ have been performed to understand the thermal-hydraulic characteristics of conventional boilers. In the past, traditional methods relied heavily on expensive experimentation and the building of scaled models, but now a more flexible and cost effective approaches are available through greater use of mathematical modeling and computer simulation [6,7]. The purpose of this work is the elaboration of a calculation program in order to estimate the heat transfer between the combustion gases and the boiler internal surfaces in 4-pass fire-tube boiler under different operating conditions. At these surfaces, an energy balance is established considering both radiation and convection heat transfer. Therefore, a set of simplifications may be considered in order to reduce the boiler complexity [8]. The boiler passes are sliced into elementary sections in the gas flow direction. Each element represents isothermal gas volumes enclosed by isothermal surfaces. The plug-flow furnace model [9] is used to simulate the heat transfer characteristics in the boiler. This model is judged more appropriate to predict the peak heat flux density and thermal parameter profiles. At the water side, a set of empirical correlations are selected in order to simulate the boiling heat transfer. The modeling validation has been made by comparing the calculated gas temperatures exiting the boiler with the measured ones for steady-state operating conditions. The comparison shows that the calculated results are in good agreement with the boiler operating data. In addition, a qualitative analysis has been made to investigate the operating pressure effect on the boiler thermal behaviour.

\section{Boiler Modeling and Simulation}

The boiler tubes are subdivided into elementary sections of length $\Delta x$ in the gas flow direction (Fig. 1). For each section an energy balance is established taking into account the generated and the transferred power in the control volume. 


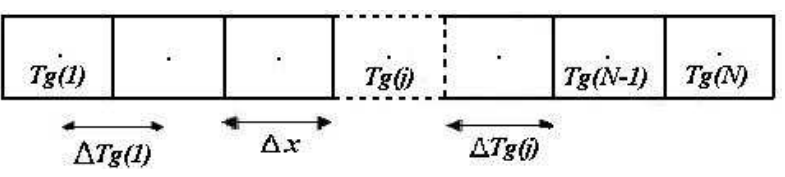

Figure 1. Nodalization scheme of the boiler tubes.

The internal energy in each segment can be calculated by the difference in gas enthalpy between the inlet and the outlet of the element (Eq. 1). In other hand, the gas energy variation represents the difference between the heat released rate and the heat transferred to the surrounding water (Eq. 2).

$$
\begin{gathered}
\Delta Q=M_{g} C p_{g} \Delta T_{g} \\
\Delta Q=\left(q_{\text {rele. }}-Q_{\text {exch. }}\right) \Delta x
\end{gathered}
$$

Then, the difference in gas temperature between two adjacent volumes, $\Delta T_{g}$, may be expressed by Eq. (3). Where, $M_{g}$ is the total mass flow rate of combustion gases and $C p_{g}$ is the gas specific heat capacity.

$$
\Delta T_{g}(j)=\left(\frac{q_{\text {rele. }}(j)-Q_{\text {exch. }}(j)}{M_{g} C p_{g}(j)}\right) \Delta \mathrm{x}
$$

The recurrence formula given by Eq. (4) enables the gas temperature $T_{g}(i)$ calculation along the flue gas flow. Where, $j=1,2 \ldots, N$, denotes the volume axial location.

$$
T_{g}(j)=T_{g}(j-1)+\Delta T_{g}(j-1)
$$

The heat release pattern along the flame can be described by exponential [15], parabolic [16] or simple form. In the present work, the parabolic form proposed by Roesler is applied [17]. Thus the fractional heat released per unit furnace length, $F$, is :

$$
F=\frac{6}{L_{f}}\left(\frac{x}{L_{f}}-\frac{x^{2}}{L_{f}^{2}}\right), \quad \text { for } 0 \leq \mathrm{x}<\mathrm{Lf}
$$

Where, $L_{f}$ is the flame length and $L$, is the furnace total length. The flame length has a great importance in defining the peak heat flux location and amplitude. The heat released rate, $q_{\text {rele }}$, is calculated by multiplying the total generated power, $Q_{f}$, by the fractional heat released along the furnace:

$$
q_{\text {rele. }}=Q_{f} F
$$

\subsection{Gas-Side Heat Transfer}

The heat transfer is calculated using the plug-flow furnace model (or long-tube) $[9,18]$. This model is more appropriate in predicting the axial distribution of the thermal parameters such as: heat flux densities, wall and gas temperatures and heat transfer coefficients. The gas within the furnace chamber is assumed to be gray and the gas temperature is uniform in each control volume cross-section and the axial radiation heat transfer is neglected. Heat transfer inside the furnace is governed by radiation and convection $[11,19]$ as:

$$
Q=g_{\text {ray }} \sigma\left(T_{g}^{4}-T_{w i}^{4}\right)+h_{g} A_{i}\left(T_{g}-T_{w i}\right)
$$

Where, $\sigma$ is the Stefan-Boltzmann constant, $h_{g}$ is the convective heat transfer coefficient from the gas to the wall, $A_{i}$ is the internal tube area, $\varepsilon_{g}$ and $\varepsilon_{w}$ are the gas emissivity, and the tube wall emissivity, respectively, and $g_{\text {ray }}$ is the total radiation transfer factor from the gas to the sink, expressed by:

$$
g_{\text {ray }}=\left[1 / \varepsilon_{p}+1 / \varepsilon_{g}-1\right]^{-1}
$$

The overall heat transfer coefficient, hi, is defined as the sum of convective and radiative heat transfer coefficients from the gas to the sink (Eq. 9). The heat transfer coefficient, $h_{g}$, is obtained from McAdam's correlation (Eq.10). Where, $k_{g}$, is the gas thermal conductivity, $d_{i}$ is the internal tube diameter.

$$
\begin{gathered}
h_{i}=h_{g}+\sigma g_{\text {ray }} \frac{T_{g}^{4}-T_{w i}^{4}}{T_{g}-T_{w i}} \\
h_{g}=0.023 \frac{k_{g}}{d_{i}} \mathrm{Re}^{0.8} \operatorname{Pr}^{0.4}
\end{gathered}
$$

\subsection{Water-Side Heat Transfer}

At the water side, the heat is transferred by the nucleate pool boiling heat transfer regime. For the furnace horizontal cylinder, the predicted boiling heat transfer coefficient is obtained according to Gorenflo correlation:

$$
h_{o}=5580 F_{P F}\left(q_{o} / 20000\right)^{0.9-0.3 P_{r}^{0.15}}
$$

Where, $q_{o}$ is the heat flux density and $F_{P F}$ is expressed by:

$$
F_{P F}=1.73 p_{r}^{0.27}+\left(6.1+0.68 /\left(1-p_{r}^{2}\right)\right) p_{r}^{2}
$$

Neighboring to the convection section tubes, the boiling heat transfer coefficient of the bundle is greater than for an individual tube, $h_{l}$ in Eq. (11). This is due to the vapor bubbles agitation enhancing the heat transfer. Taking into account this effect [20], the heat transfer coefficient of the convection section tubes is calculated by:

$$
h_{o}=h_{1}\left(1+\frac{1}{2+q_{o} / 1000}\right)
$$

\section{Work Procedure}

\subsection{Boiler Description}

The studied unit is a 4-pass PFTA 500HP water backed fire-tube boiler. This type of boilers is firstly introduced in 1978 by the Johnston Boiler Company [10]. These boilers have the benefits of low maintenance costs, high reliability, and high efficiency reaching $90 \%$. It can be fired by natural gas or fuel oil. A cross-section of the boiler is given in Fig. 2 . 


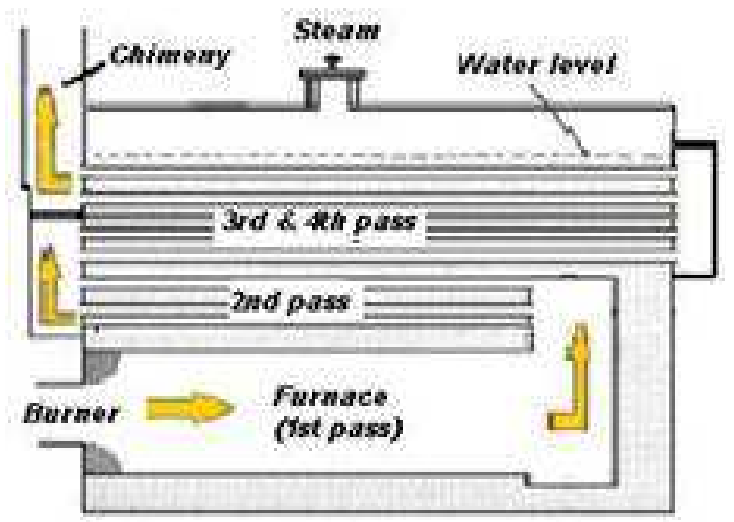

Figure 2. Typical 4-pass fire-tube boiler.

The main steam boiler characteristics are:

- Steam generation: 7.6 ton $/ \mathrm{h}$,

- Maximum operating pressure: 25 bars,

- Total water amount: $12 \mathrm{~m}^{3}$,

- Total tube number: 232 ,

- Total heating surfaces: $237.5 \mathrm{~m}^{2}$,

- Furnace length \&internal diameter: $5 \mathrm{~m} \& 1.067 \mathrm{~m}$.

From heat transfer point of view, it consists mainly of two parts: the radiation section and the convection section. The first (1st pass), is a horizontal cylindrical tube in which the fuel is burned and heat is generated. Heat transfer within this section is performed mainly by radiation, although convection may contribute to less than $20 \%$ [11]. The convection section is a horizontal smoke-tube banks located above the 1st pass, recovering additional heat from the furnace gases at a lower temperature level better than the radiant section tubes $[12,13]$. All tubes are immersed in water which absorbs the heat enough to change into a vapor state. The main heat transfer mechanism in this section is the convection. Fuel and air are forced into the furnace by the burner to produce heat. The number of tubes in each pass is selected to give similar velocities in each pass. Because of the forced-draft fan, the boiler is pressurized and there may be a slight positive pressure at the flue gas outlet [14]. This allows higher gas velocities in the unit. The hot gases move from the radiation section toward the convection section, crossing the boiler passes and finally escape by the chimney to the atmosphere.

\subsection{Calculation Procedure}

The overall calculation scheme for the complete model is presented in Fig. 3.

Thermal properties of the combustion products like, emissivity, heat capacity, thermal conductivity, are correlated versus gas temperature in order to accurately predict there variation along the flue gas flow. The material-tube conductivity is also correlated with the wall temperature and its emissivity is: $\varepsilon_{p}=0.85$.

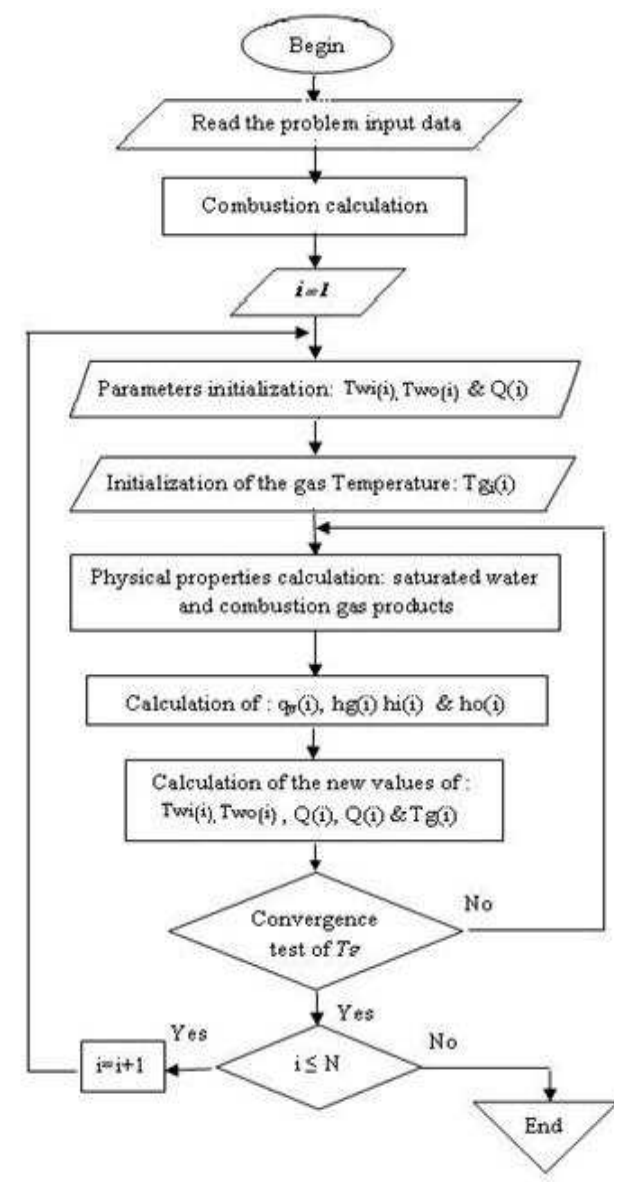

Figure 3. Adopted sequences for solution.

\section{Results and Discussions}

\subsection{Program Validation}

In order to validate the calculation program, the predicted gas temperature exiting the boiler is compared with the operating data of the PFTA 500HP fire-tube boiler at different operating pressures and for three different types of fuel.

This boiler operating data are found in Ref. [10]. The comparison between the predicted and the measured gas temperatures exiting the boiler are summarized in Tables 1, 2 and 3 . As could be seen, a good agreement with the boiler operating data is obtained.

Table 1. Boiler operating with Natural gas

\begin{tabular}{lll}
\hline \multirow{2}{*}{$\begin{array}{l}\text { Operating } \\
\text { pressure }\end{array}$} & Gas flow rate $(\mathbf{0 . 1 1} \mathbf{~ k g} / \mathbf{s})$ \\
\cline { 2 - 3 } & $\begin{array}{l}\text { Experimental } \\
\text { gas Temp. }\left({ }^{\circ} \mathbf{C}\right)\end{array}$ & $\begin{array}{l}\text { Calculation } \\
\text { gas Temp. }\left({ }^{\circ} \mathbf{C}\right)\end{array}$ \\
\hline 0.689 & 136.7 & 149 \\
3.447 & 168.9 & 180 \\
6.895 & 191.7 & 201.5 \\
10.34 & 207.2 & 216.6 \\
13.79 & 219.4 & 228.6 \\
17.24 & 230 & 238.6 \\
20.68 & 238.9 & 246.3 \\
\hline
\end{tabular}


Table 2. Boiler operating with \#2 fuel oil

\begin{tabular}{lll}
\hline \multirow{2}{*}{$\begin{array}{l}\text { Operating } \\
\text { pressure }\end{array}$} & \multicolumn{2}{l}{ Fuel flow rate $(\mathbf{0 . 1 1 4} \mathbf{~ k g} / \mathbf{s})$} \\
\cline { 2 - 3 } & $\begin{array}{l}\text { Experimental } \\
\text { gas Temp. }\left({ }^{\circ} \mathbf{C}\right)\end{array}$ & $\begin{array}{l}\text { Calculation } \\
\text { gas Temp. }\left({ }^{\circ} \mathbf{C}\right)\end{array}$ \\
\hline 0.689 & 141.7 & 150.7 \\
3.447 & 173.9 & 181.7 \\
6.895 & 196.1 & 203.2 \\
10.34 & 212.2 & 218.3 \\
13.79 & 224.4 & 230.2 \\
17.24 & 235 & 240.2 \\
20.68 & 243.9 & 248.8 \\
\hline
\end{tabular}

Table 3. Boiler operating with \#6 fuel oil

\begin{tabular}{lll}
\hline \multirow{2}{*}{$\begin{array}{l}\text { Operating } \\
\text { pressure }\end{array}$} & \multicolumn{2}{l}{ Fuel flow rate $(\mathbf{0 . 1 3 4} \mathbf{~ k g} / \mathbf{s})$} \\
\cline { 2 - 3 } & $\begin{array}{l}\text { Experimental } \\
\text { gas Temp. }\left({ }^{\circ} \mathbf{C}\right)\end{array}$ & $\begin{array}{l}\text { Calculation } \\
\text { gas Temp. }\left({ }^{\circ} \mathbf{C}\right)\end{array}$ \\
\hline 0.689 & 147.2 & 158.1 \\
3.447 & 180 & 189 \\
6.895 & 202.8 & 210.4 \\
10.34 & 218.9 & 225.4 \\
13.79 & 231.7 & 237.2 \\
17.24 & 242.2 & 247.2 \\
20.68 & 251.7 & 255.8 \\
\hline
\end{tabular}

The maximum error in predicting the boiler outlet gas temperature is $9 \%$. The discrepancies are probably due to simplifications introduced in the numerical model. It can be also observed that all the calculated results overestimate the measured ones. This could be due to neglecting heat transfer at the transitions box between the boiler passes.

\subsection{Boiler Performances}

In this section, a qualitative analysis is made in order to study the operating pressure effect on the heat transfer performances. The axial profiles of gas temperature, heat flux density, heat transfer coefficient, wall temperatures, and heat exchanged power along the boiler passes are analyzed. Fig. 4 shows that the operating pressure hasn't a great influence on the gas temperature. The heat flux distribution along the boiler tubes is shown in Fig. 5.

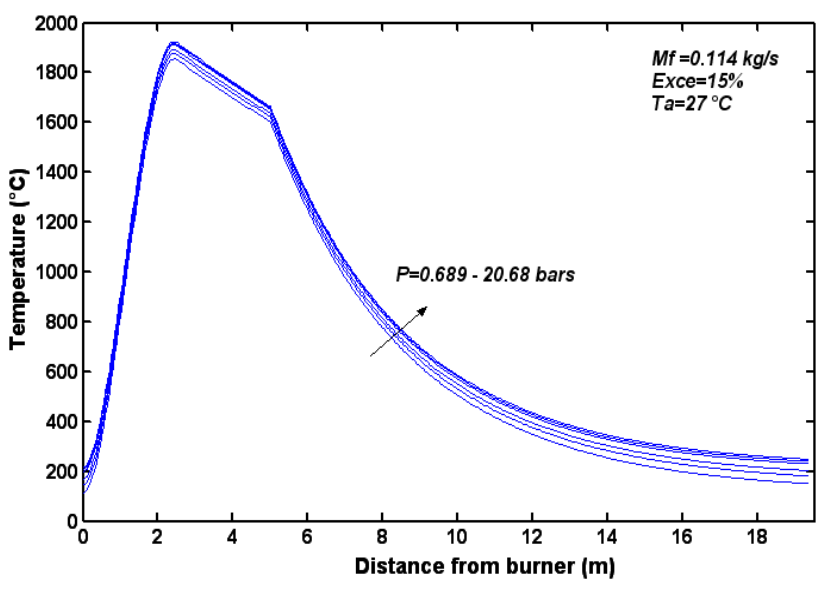

Figure 4. Gas flow temperature profile.

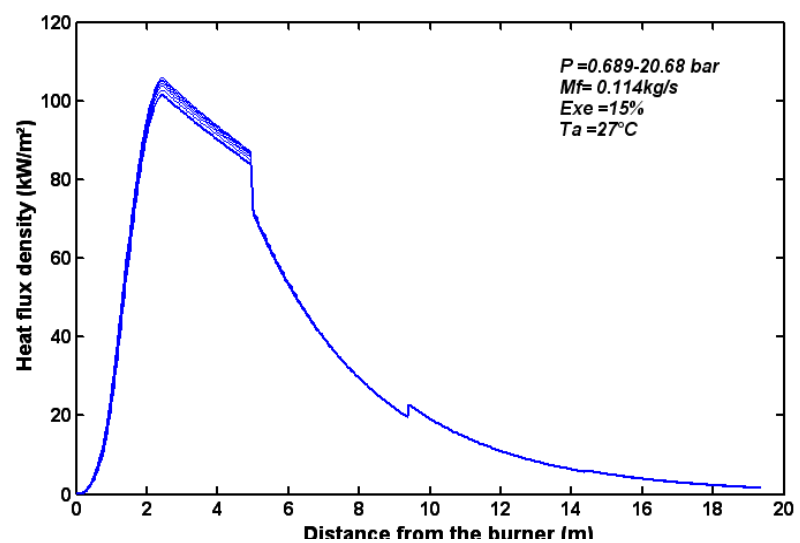

Figure 5. Heat flux density distribution.

The peak heat flux is $91.9 \mathrm{~kW} / \mathrm{m}^{2}$. It is clear that the pressure variation hasn't a remarkable effect on the heat flux especially in the convection section. In fact, the boiler operating pressure influences the water physical properties, and consequently, the boiling heat transfer. Fig. 6 shows that an increase in the system pressure increases the boiling heat transfer, where the maximum value is $15.81 \mathrm{~kW} / \mathrm{m}^{2} \mathrm{~K}$. A significant heat transfer is observed in the radiation section, due to the slight elevation in the wall temperature at this region (Fig. 7) which increases the bubble vapor generation. The internal and external wall temperature profiles are plotted under the pressure variation.

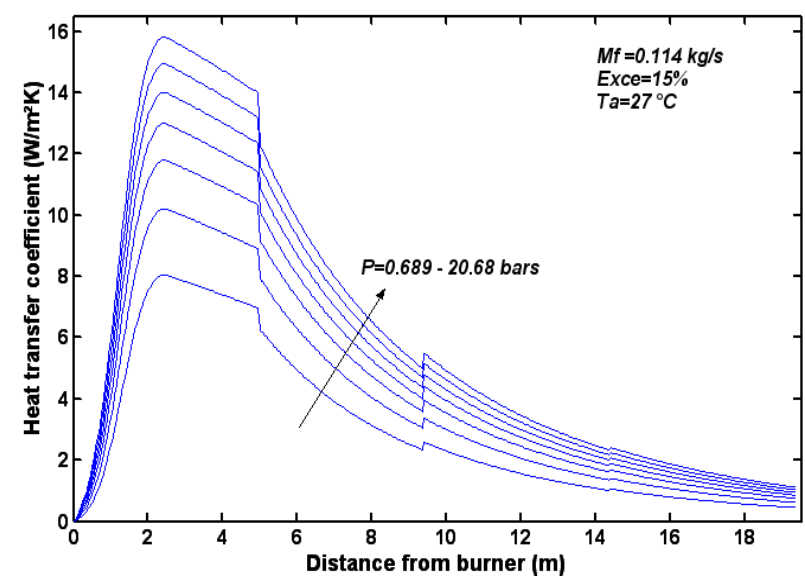

Figure 6. Heat transfer coefficient variations.

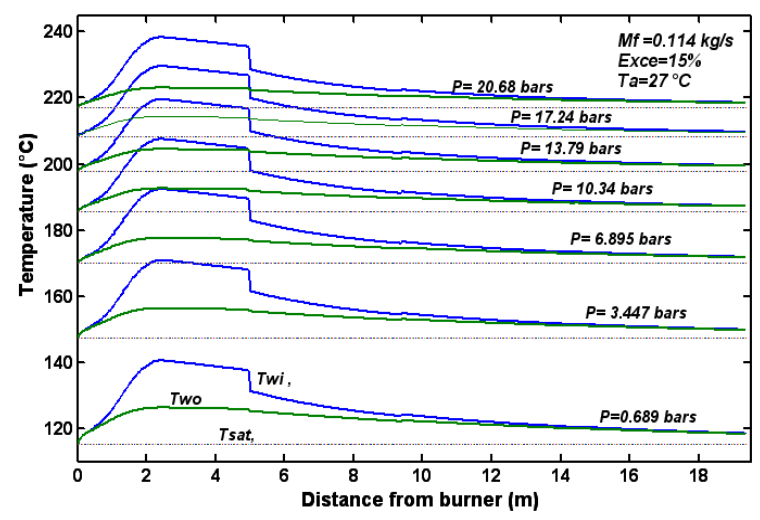

Figure 7. Wall temperature distribution. 
In Fig. 7, as the pressure increases, the saturation temperature increases rising the wall temperature. The difference between the inner and the outer wall temperatures is widened due to the diminishing in the thermal conductivity of the material tube at this location.

Fig. 8 shows the heat transferred power distribution along the combustion chamber. The numerical calculation results showed that the amount heat transferred to the water is 1.06 MW. In the combustion chamber (1st pass) the radiation heat transfer is $877 \mathrm{~kW}$ representing $82.65 \%$ of the total exchanged power and the convection part is $184 \mathrm{~kW}$ denote that the convection process contribute by about $17.34 \%$ in the total heat transfer. It is obvious that the heat transfer within the boiler furnace is performed mainly by radiation.

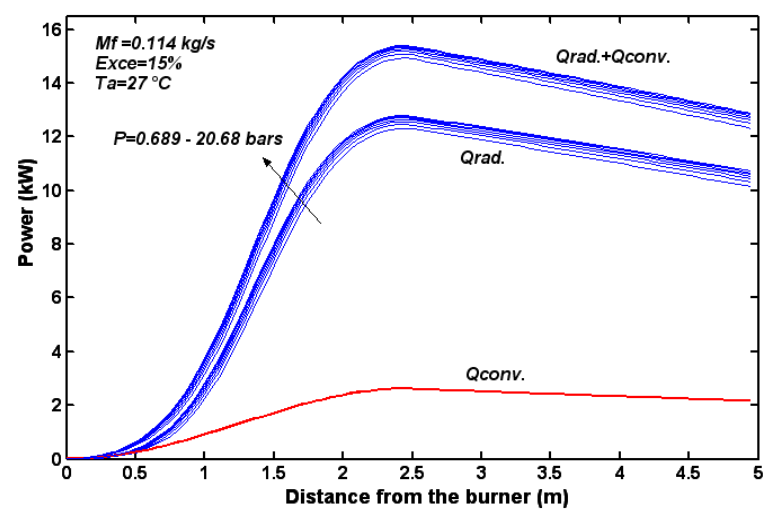

Figure 8. Exchanged power in the furnace.

Fig. 9 depicts the heat transferred power along the 4-pass of the boiler. The total exchanged power from the combustion gases to the boiler water is $4.63 \mathrm{MW}$. In the convection section, $3.57 \mathrm{MW}$ is absorbed by the tube bundles.

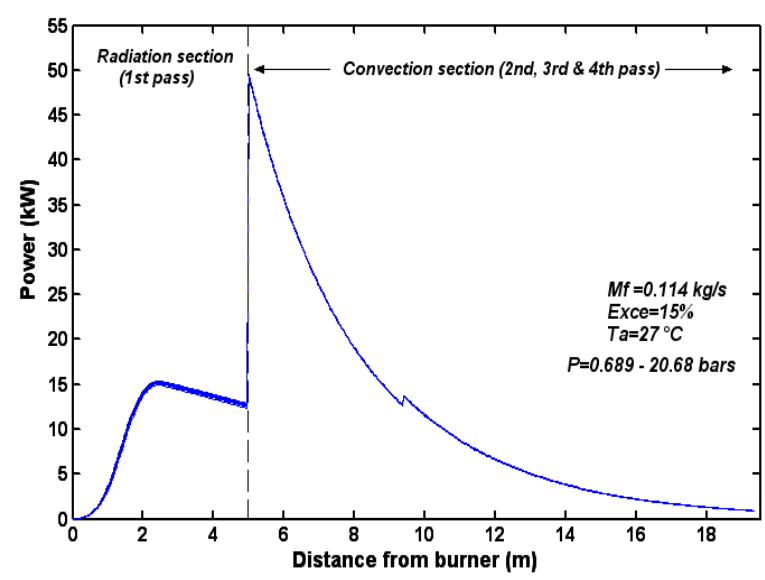

Figure 9. Power distribution in the boiler.

This represents $77.1 \%$ of the total exchanged power in the whole boiler whereas in the furnace, the rate of transferred power is corresponds to $22.9 \%$. This is mainly due to the large heat transfer surface of the convection section compared to the radiation section.

\section{Conclusion}

In this study a numerical simulation of a 4-pass fire-tube boiler is performed using a coded computer program. The modeling approach consists of subdividing the boiler tubes into elementary volumes in the gas flow direction. The gas fuel combustion and heat transfer laws from hot gases to the boiling water are taken into account according to adequate correlations. The heat exchange between the combustion gases and the boiler internal walls is therefore estimated according to a numerical scheme. The calculated results have been compared to the boiler operating data for different steady-state regimes, and good agreement is generally obtained. The operating pressure effect on the boiler heat transfer characteristics has been investigated. The calculation shows that, the prevailing mechanism of heat transfer in the 4-pass fire-tube boiler is convection, which accounts for over $80 \%$.

\section{References}

[1] D. Annaratone, Smoke-tube boiler, Steam Generators, 87-101, Springer-Verlag Berlin Heidelberg, 2008.

[2] A. Rahmani and A. Dahia, "Thermal-hydraulic modeling of the steady-state operating conditions of a fire-tube boiler", International Journal of Nuclear Technology \& Radiation Protection, 2009, pp. 24, 29-37

[3] J. Taler, "A Method of determining local heat flux in boiler furnaces", Int. J. Heat \& Mass Transfer, vol. 35, 1992, pp. $1625-1634$.

[4] B.J. Huang, R.H. Yen and W.S. Shyu, "A steady-state thermal performance model of fire-tube shell boilers", Int. J. Engineering for Gas Turbines and Power, vol. 110, 1988, pp. 173-179.

[5] J. Ganan, A. AL-Kassir, J.F. Gonzalez, J. Turegano and A.B. Mirand, "Experimental study of fire tube boilers performance for public heating", Applied Thermal Engineering, vol. 25, 2005, pp. 1650-1656.

[6] B.R. Adams, H.S. Shim, S.R. Wu, W.C. Chang, H.W. Chiao, and S.L. Chen, "Evaluation of NOx reduction strategies in an oil-fired furnace", CFD Proceeding, 4th Asia-Pacific Conference on Combustion, Nanjing, China, November 2003, pp. 24-26.

[7] M. Orstnerhof, G. Meister, M. Jöller, J. Dahl, M. Braun and S. Kleditzsch, "CFD simulation of ash de posit formation in fixed bed biomass furnaces and boilers", Progress in Computational Fluid Dynamics, vol. 6, 2006, pp. 248-261.

[8] B. Leckner, "Radiation from flames \& gases in a cold-wall combustion chamber", Heat \& Mass Transfer, vol. 13, 1970, pp. 185-197.

[9] J.S. Truelove, Thermal and hydraulic design of heat exchangers: furnace and combustion chamber, Heat Exchanger Design Handbook, Hemisphere Publishing Corporation, New-York, USA, 1983.

[10] Home page of "Johnston Boiler Company", http://www.jhonstonboiler.com. 
[11] R. Borghi and M. Destriau, La combustion et les flammes, Edition Technip, Paris, 1995.

[12] G.F. Hewitt and G.L. Shires, Process Heat Transfer, CRC Press, Boca Raton, Fla., USA, 1994.

[13] M. Tamotsu, "Fire tube boiler", Applied Thermal Engineering, vol. 16, 1996, pp. 3-8.

[14] P.J. Potter, Power plant theory and design, 2nd Edition, Ronald Press Co., New York, USA, 1959.

[15] J.M. Rhine and R.J. Tucker, Modeling of Gas-Fired Furnace and Boiler, 1st Edition, British Gas Publication, Berkshire, 1991.

[16] F.C. Roesler "Theory of radiative heat transfer in co-current tube furnaces", Chemical Engineering Science, 22 1997, pp. $1325-1336$.
[17] F. Farhadi, M. Bahrami, M.M. Babaheidari and Y.M. Hashemi, "Radiative model for the furnace side of a bottom-fired reformer", Applied Thermal Engineering, vol. 25, 2005, pp. 2398-2511.

[18] M. Gao and L.X. Kong, "Numerical simulation of heat and mass transfer in fluidized bed heat treatment furnaces", J. Material Processing Technology, vol. 125, 2002, pp. 170-178.

[19] R. Siegel, J.R. Howell, Thermal radiation heat transfer, 2nd Edition, Mc Graw-Hill Book Company, 1980.

[20] H.D. Baehr and K. Stephan, Heat and mass transfer, 2nd Edition, Springer-Verlag, Berlin, Heidelberg, 2006. 